\title{
Analisis Hemming Sheet Metal dengan Variasi Jenis dan Ketebalan Material
}

\author{
(Hemming Sheet Metal Analysis with Variation in Material Type and Thickness) \\ Vinsentius Bram Armunanto ${ }^{a}$, Erico S Chrissandi ${ }^{b}$, Herman Yosef ${ }^{c}$, Krisna G Hernanto ${ }^{d}$ \\ Pujosakti Herdhianto ${ }^{\mathrm{e}}$, Yesaya Alfa Deta ${ }^{f}$ \\ a,b,c,d,e,f ATMI Polytehcnic \\ Jalan Mojo 1, Surakarta, Indonesia \\ Telephone : 62271714466 / fax : 62271714390 \\ e-mail: vbaatmi@yahoo.coma / bram_a@atmi.ac.id
}

\begin{abstract}
Abstrak
Perkembangan industri manufaktur semakin pesat, sebagai buktinya adalah efisiensi dan kecepatan proses pembuatan produk. Proses pemesinan meliputi pemotongan, pembentukan, pelapisan, perlakuan panas, dan pengecoran. Proses pembengkokan termasuk dalam proses pembentukan, termasuk bahan pelat baja. Khusus proses pembengkokan dengan sudut 180 derajat (hemming), sering terjadi kegagalan dengan adanya goresan, cacat atau patah. Pemilihan bahan pelat yang sesuai akan menghasilkan produk yang optimal. Penyebab kegagalan lentur dapat terjadi karena parameter proses lentur (gaya lentur, metode, ketebalan, dan tipe pelat) tidak sesuai. Penelitian dan pengujian menggunakan standar ASTM E290 untuk menemukan, menganalisis, dan membuktikan kegagalan dalam proses hemming. Hasilnya adalah material hasil proses hemming yang bebas dari cacat atau patah dan bisa menjadi data pendukung terkait desain produk dalam Work Fabrikasi (WF) di PT ATMI Solo.
\end{abstract}

Kata kunci: metode bending; proses hemming; ASTM E290.

\begin{abstract}
The development of manufacturing industry is more rapidly, as a proof is the effeciency and speed of machining process of product manufacture. A machining process covers cutting, forming, coating, heat treatment, and casting. The bending process is included in the forming process, especially for steel plate material. The bending process uses bending tools either manual or automatic process using the program. Selection of suitable plate material will produce the optimal product, which is product free of scratch, crack or defect.The cause of bending failure can occur because the bending process parameters (bending force, methods, thickness and plate type) are not appropriate. Bending methods include $v$ blending, $u$ blending, $r$ blending and hemming. Research and testing are needed to discover, analyze, and prove failure in hemming process. The result is expected to be supporting data related to product design in Work Fabrication (WF) at PT ATMI Solo.
\end{abstract}

Keywords: bending methods, hemming process, work fabrication

\section{Pendahuluan}

Efisiensi proses dan pemenuhan kualitas produk yang baik menunjang perkembangan teknologi manufaktur. Proses manufaktur meliputi pemotongan, pembentukan, pelapisan, perlakuan panas dan pengecoran. Bending sheet metal merupakan bagian dari proses pembentukan dimana proses penekukan atau pembengkokan menggunakan punch untuk menekan pelat dan menggunakan dies sebagai penahan pelat untuk membentuk sudut sesuai tuntutan gambar.

Metode bending sheet metal dapat dikelompokkan berdasarkan bentuk penekukan meliputi $v$ bending, $u$ bending, $r$ bending dan hemming [1].Bentukan hemming berupa pelat 
dengan sudut tekukan $180^{\circ}$, berasal dari kata "hem" yang berarti tekukan di tepi [3]. Faktor yang mempengaruhi proses hemming adalah ketebalan pelat, peralatan pendukung, dan pelumasan. Proses hemming memiliki dua variasi bentuk/kontur, yaitu straight hemming dan radius hemming. Ketidaksesuaian proses straight hemming bisa berakibat crack dan recoil/warp [5]. Pada proses radius hemming bisa terjadi wrinkling / splitting dan hem out.

Penelitian ini dilakukan untuk mengetahui pengaruh metode hemming pada : (1) jenis material pelat baja karbon rendah, yaitu: mild steel SPHC, mild steel SPCC, stainless steel 201 dan stainless steel 304[4].sesuai material yang digunakan di unit Work Fabrication (WF) PT. ATMI Solo, (2) ketebalan dan jenis material yang berbeda, (3) mesin bending AMADA PROMECAM dengan seri : ITS 10030 T10508.

\section{Metode}

Proses pengujian diawali dengan pemotongan material searah serat, dimensi material uji $38 \mathrm{~mm} \times 76 \mathrm{~mm}$ (tebal sesuai daftar) dengan metode ASTM E290 [8] menggunakan mesin Shearing Promecam tipe GTH 430.

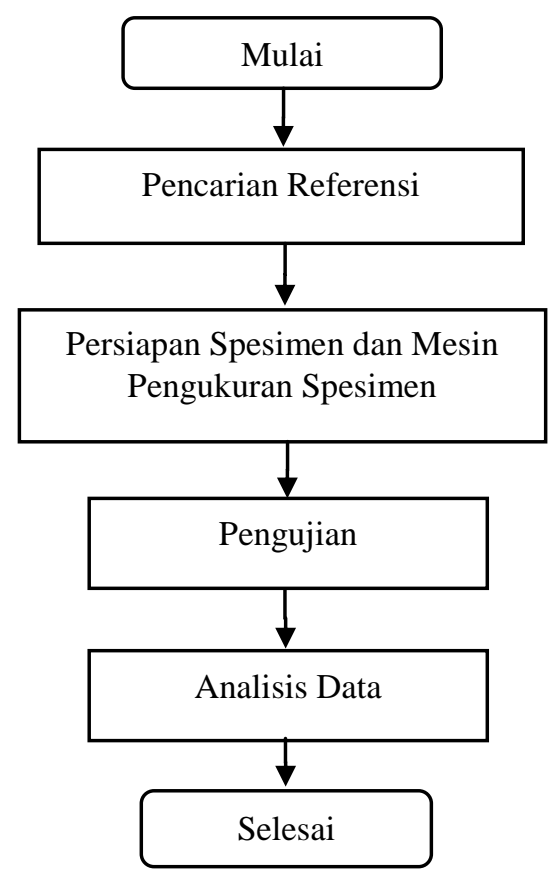

Gambar 2.1. Flowchart Penelitian

Permasalahan yang dibahas akan dibatasi pada:

1. Mesin bending yang digunakan adalah AMADA PROMECAM dengan seri ITS 10030 T10508 dengan dies 10409 dan punch 103 untuk pre-hemming; dies khusus dan punch 220 untuk hemming. Kekerasan dies 43-48 HRc, diverifikasi dengan ID 401.103.01 oleh divisi maintenance di PT. ATMI Solo.

2. Material uji yang digunakan mild steel SPHC, mild steel SPCC, SUS 201 dan SUS 304 sesuai pemakaian material di unit WF PT. ATMI Solo, produk dari PT. Krakatau Steel (Persero) Tbk.

3. Dimensi material uji $38 \mathrm{~mm} \times 76 \mathrm{~mm}$ sesuai dengan metode ASTM E290 menggunakan mesin Shearing Promecam dan dipotong searah serat baja.

4. Metode hemming digunakan sebagai proses penekukan material.

5. Bevel Protractor yang sudah diverifikasi dengan ID U.TE.BP360.TS.1. oleh divisi Measuring di PT. ATMI Solo digunakan untuk mengukur sudut hasil bending.

6. Benda uji bersih dari kotoran dan chips pada ujung potongan dengan visual checking sesuai dengan metode ASTM E290. 


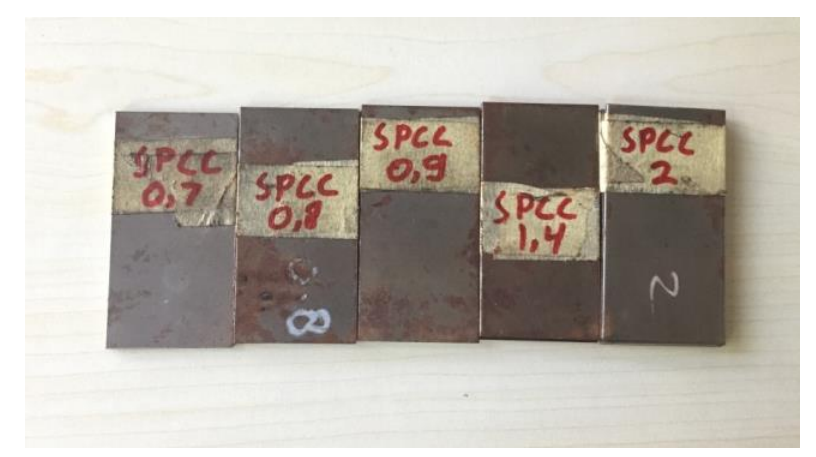

Gambar 2.2. Spesimen Uji Hemming (ASTM E290)

Pemilihan jenis material dan variasi ketebalan, dipilih sebagai berikut :

SPHC, ketebalan : $1,4 \mathrm{~mm} ; 1,8 \mathrm{~mm} ; 2,8 \mathrm{~mm} ; 3,2 \mathrm{~mm} ; 3,8 \mathrm{~mm}$.

SPCC, ketebalan : $0,7 \mathrm{~mm} ; 0,8 \mathrm{~mm} ; 0,9 \mathrm{~mm} ; 1,4 \mathrm{~mm} ; 2,0 \mathrm{~mm}$.

St.St.201, ketebalan : $0,5 \mathrm{~mm} ; 1,0 \mathrm{~mm} ; 1,2 \mathrm{~mm} ; 2,0 \mathrm{~mm}$.

St.St.304, ketebalan : $0,5 \mathrm{~mm} ; 1,0 \mathrm{~mm} ; 1,2 \mathrm{~mm} ; 2,0 \mathrm{~mm}$.

Pengujian terhadap kandungan material yang terdapat pada spesimen uji dilakukan setelah proses pemotongan spesimen uji. Pengujian material dilakukan di Polman Ceper dengan metode uji spektro.Proses pengujian hemming dilakukan setelah proses pemotongan spesimen uji, pengujian diawali dengan proses pre-hemming, dimana pelat ditekuk sebesar $145^{\circ}-150^{\circ}$ untuk memudahkan proses bending pelat terkait tonase proses pembentukan, digunakan metode three points bending.

Rumus 3 points bending [6]:

$$
F=\frac{48 E \times I \times W_{0}}{L^{3}}
$$

Inersia (I) dirumuskan sebagai berikut [7]:

$$
I=\frac{a^{3} \times b}{12}
$$

Keterangan :

$\begin{array}{lll}\mathrm{F} & \text { : gaya 3 points bending } & (\mathrm{N}) \\ \mathrm{E} & \text { : elastisitas pelat } & \left(\mathrm{N} / \mathrm{mm}^{2}\right) \\ \text { I } & \text { : momen inersia } & \left(\mathrm{mm}^{4}\right) \\ \text { Wo } & \text { : titik mati bawah dies } & (\mathrm{mm}) \\ \text { L } & \text { : lebar bukaan dies } & (\mathrm{mm}) \\ \text { a } & \text { : tebal pelat } & (\mathrm{mm}) \\ \text { b } & \text { : lebar pelat } & (\mathrm{mm})\end{array}$

Untuk lebar bukaan dies $(\mathrm{L})$ terdapat ketentuan :

- untuk ketebalan $<1,5 \mathrm{~mm}$, menggunakan lebar bukaan dies $8 \mathrm{~mm}$.

- untuk ketebalan $1,5 \mathrm{~mm} \leq x \leq 3,2 \mathrm{~mm}$, menggunakan lebar bukaan dies $10 \mathrm{~mm}$.

- untuk ketebalan $>3,2 \mathrm{~mm}$, menggunakan lebar bukaan dies $18 \mathrm{~mm}$.

Pengujian dilakukan sebanyak 3 kali untuk setiap ketebalan material dengan pengujian pertama menggunakan besaran tonase hasil perhitungan. Pengujian kedua menggunakan besaran tonase yang dibutuhkan untuk mencapai sudut pre hemming. Pengujian ketiga menggunakan besaran tonase yang sama dengan pengujian kedua untuk memastikan bahwa sudut pre hemming yang tercapai tepat. Pengukuran sudut setelah proses prehemming menggunakan bevel protractor. Pengukuran dilakukan untuk mengetahui sudut pre-hemming yang terjadi. 
Pengujian terakhir adalah hemming, untuk mengetahui pengujian berhasil atau apakah terjadi kerusakan. Perhitungan tonase hemming dilakukan menggunakan metode interpolasi. Penentuan tonase hemming dibutuhkan untuk meminimalisir kesalahan proses. Interpolasi tonase hemming berdasarkan tabel 2.1.

Tabel 2.1. Tabel Tonase Hemming AMADA

\begin{tabular}{|c|c|c|c|c|c|c|c|c|c|}
\hline \multicolumn{5}{|c|}{ Material : SPCC, SS41 } & \multicolumn{5}{|c|}{ Material : SUS } \\
\hline \multirow{3}{*}{$\begin{array}{l}\text { Sheet } \\
\text { thick- } \\
\text { ness } \\
(\mathrm{mm})\end{array}$} & \multicolumn{4}{|c|}{ Bending shape } & & \multicolumn{4}{|c|}{ Bending shape } \\
\hline & \multicolumn{2}{|c|}{ C shape } & \multicolumn{2}{|c|}{2 r shape } & & \multicolumn{2}{|c|}{ C shape } & \multicolumn{2}{|c|}{2 r shape } \\
\hline & Tonnage & C & Tonnage & $2 r$ & & Tonnage & C & Tonnage & $2 r$ \\
\hline 0.6 & 9 & 3 & 23 & 1.2 & 0.6 & 15 & 3 & 35 & 1.2 \\
\hline 0.8 & 12 & 3 & 32 & 1.6 & 0.8 & 20 & 3 & 50 & 1.6 \\
\hline 1.0 & 15 & 3.5 & 40 & 2.0 & 1.0 & 25 & 3.5 & 60 & 2.0 \\
\hline 1.2 & 17 & 3.5 & 50 & 2.4 & 1.2 & 26 & 3.5 & 80 & 2.4 \\
\hline 1.6 & 24 & 3.5 & 63 & 3.2 & 1.5 & 38 & 3.5 & 95 & 3.0 \\
\hline 2.0 & 30 & 5.5 & 80 & 4.0 & 2.0 & 50 & 5.5 & 130 & 4.0 \\
\hline 2.6 & 55 & 6.5 & 90 & 5.2 & 2.5 & 90 & 6.5 & 180 & 5.0 \\
\hline 3.2 & 70 & 8.0 & 100 & 6.4 & 3.0 & 100 & 8.0 & 210 & 6.0 \\
\hline 4.5 & 105 & 11.3 & 200 & 9.0 & 4.0 & 140 & 11.3 & 280 & 8.0 \\
\hline
\end{tabular}

Metode yang digunakan untuk pengecekan spesimen uji menggunakan visual inspection sesuai dengan standar ASTM E290. Metode Visual inspection digunakan untuk menemukan cacat permukaan dan korosi menggunakan mata telanjang atau dengan lensa pembesar (borescope). Cacat permukaan yang dapat dilihat berupa crack, patah dan recoil/warp.

\section{Hasil dan Pembahasan}

Berdasarkan pengujian hemming menggunakan mesin bending AMADA PROMECAM dengan seri ITS 10030 T10508 diperoleh data sudut bentukan pre hemming dan kerusakan yang terjadi pada proses hemming. Data pengujian dimasukkan dalam tabel dan dibuat grafik untuk membandingkan sudut yang terbentuk saat menggunakan tonase perhitungan dan tonase real dan untuk perbandingan tonase perhitungan dan tonase real

Tabel 3.1. Tabel Pengujian Hemming Material SPHC

\begin{tabular}{|c|c|c|c|c|}
\hline $\begin{array}{l}\text { Jenis } \\
\text { Pelat }\end{array}$ & Ketebalan (mm) & Kode & Crack & $\begin{array}{l}\text { erusakan } \\
\text { Recoil / Warp }\end{array}$ \\
\hline \multirow{15}{*}{ SPHC } & \multirow{3}{*}{1,4} & A1-1 & - & - \\
\hline & & A1-2 & - & - \\
\hline & & A1-3 & - & - \\
\hline & \multirow{4}{*}{1,8} & A2-1 & - & - \\
\hline & & A2-2 & - & - \\
\hline & & A2-3 & - & - \\
\hline & & A3-1 & - & - \\
\hline & \multirow[t]{3}{*}{2,8} & A3-2 & - & - \\
\hline & & A3-3 & - & - \\
\hline & & A4-1 & - & - \\
\hline & \multirow[t]{3}{*}{3,2} & A4-2 & - & - \\
\hline & & A4-3 & - & - \\
\hline & & A5-1 & $\sqrt{ }$ & - \\
\hline & \multirow[t]{2}{*}{3,8} & A5-2 & $\sqrt{ }$ & - \\
\hline & & A5-3 & $\sqrt{ }$ & - \\
\hline
\end{tabular}

Berdasarkan Tabel 3.1 yaitu pengujian hemming sheet metal dengan spesimen SPHC tidak terlihat / terjadi recoil / warp. Pengujian hemming pada material SPHC ketebalan $3,8 \mathrm{~mm}$ terdapat crack. Hasil pengujian hemming pelat SPHC dengan ketebalan 1,4 $\mathrm{mm}$; $1,8 \mathrm{~mm} ; 2,8 \mathrm{~mm} ; 3,2 \mathrm{~mm}$ berhasil di-hemming dan tidak mengalami crack atau recoil / warp 
dikarenakan radius ujung punch yang digunakan sesuai (ukuran $\mathrm{R} 1 \mathrm{~mm}$ ). Hasil pengujian hemming pelat SPHC : $3,8 \mathrm{~mm}$ mengalami crack karena radius punch terlalu kecil dan juga pengaruh kandungan karbon yang tinggi $(0,175 \%)$.

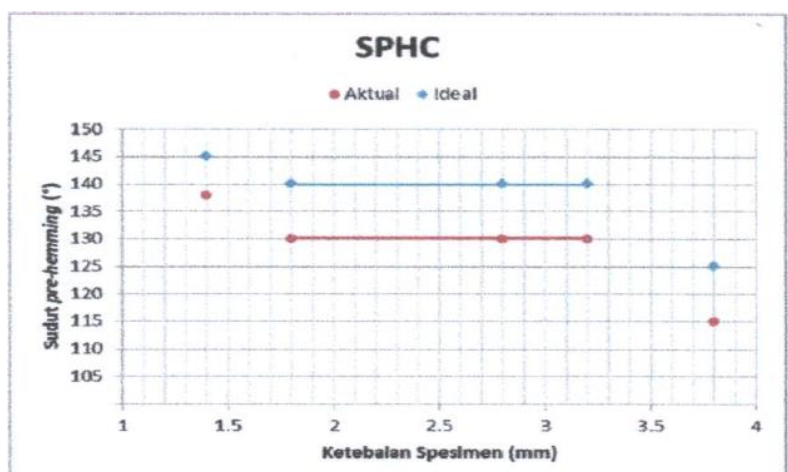

Gambar 3.1. Perbandingan sudut spesimen SPHC Menggunakan tonase perhitungan dengan tonase real

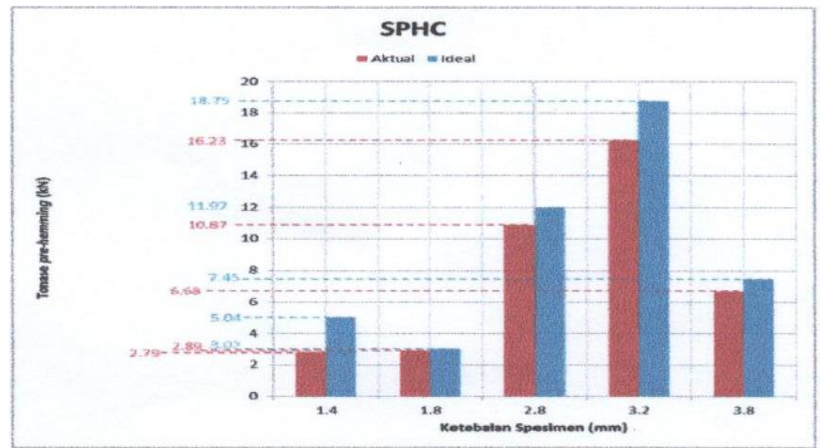

Gambar 3.2. Perbandingan tonase spesimen SPHC untuk mencapai sudut yang digunakan untuk pre-hemming.

Tabel 3.2. Tabel pengujian Hemming Material SPCC

\begin{tabular}{|c|c|c|c|c|}
\hline \multirow{2}{*}{$\begin{array}{l}\text { Jenis } \\
\text { Pelat }\end{array}$} & \multirow{2}{*}{ Ketebalan $(\mathrm{mm})$} & \multirow{2}{*}{ Kode } & \multicolumn{2}{|c|}{ Kerusakan } \\
\hline & & & Crack & Recoil \\
\hline \multirow{15}{*}{ SPHC } & \multirow{4}{*}{0,7} & B1-1 & - & $\sqrt{ }$ \\
\hline & & B1-2 & - & $\sqrt{ }$ \\
\hline & & B1-3 & - & $\sqrt{ }$ \\
\hline & & B2-1 & - & $\sqrt{ }$ \\
\hline & \multirow[t]{3}{*}{0,8} & B2-2 & - & $\sqrt{ }$ \\
\hline & & B2-3 & - & $\sqrt{ }$ \\
\hline & & B3-1 & - & $\sqrt{ }$ \\
\hline & \multirow{3}{*}{0,9} & B3-2 & - & $\sqrt{ }$ \\
\hline & & B3-3 & - & $\sqrt{ }$ \\
\hline & & B4-1 & - & $\sqrt{ }$ \\
\hline & \multirow{3}{*}{1,4} & B4-2 & - & $\sqrt{ }$ \\
\hline & & B4-3 & - & $\sqrt{ }$ \\
\hline & & B5-1 & - & - \\
\hline & \multirow[t]{2}{*}{2} & B5-2 & - & - \\
\hline & & B5-3 & - & - \\
\hline
\end{tabular}

Berdasarkan Tabel 3.2 pengujian hemming sheet metal pada spesimen SPCC tidak terjadi crack, ketebalan $0,7 \mathrm{~mm} ; 0,8 \mathrm{~mm} ; 0,9 \mathrm{~mm} ; 1,4 \mathrm{~mm}$ terdapat recoil / warp dikarenakan material memiliki sifat ulet akibat proses pembuatannya (pengerolan dingin) dan ujung dies hemming yang digunakan tidak sesuai. Hasil pengujian hemming pelat SPCC dengan ketebalan $2 \mathrm{~mm}$ berhasil dan tidak mengalami crack dan recoil / warp karena menggunakan dies khusus. 


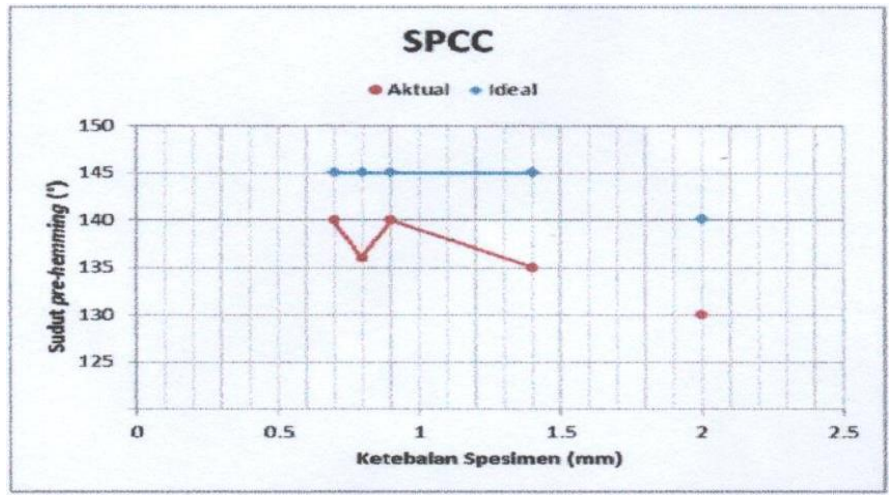

Gambar 3.3. Perbandingan sudut spesimen SPCC menggunakan tonase perhitungan dengan tonase real

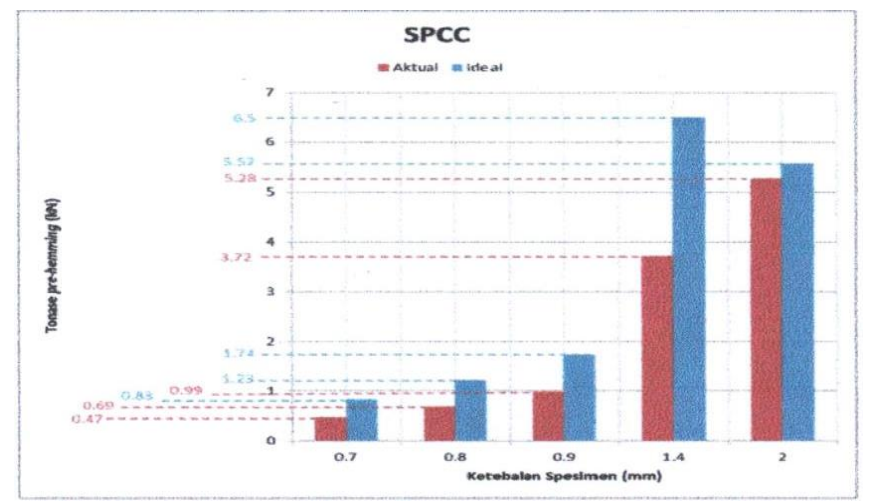

Gambar 3.4. Perbandingan tonase spesimen SPCC untuk mencapai sudut yang digunakan untuk pre-hemming.

Tabel 3.3. Tabel pengujian Hemming Material SUS 201

\begin{tabular}{|c|c|c|c|c|}
\hline $\begin{array}{l}\text { Jenis } \\
\text { Pelat }\end{array}$ & Ketebalan $(\mathrm{mm})$ & Kode & Crack & $\begin{array}{l}\text { Kerusakan } \\
\quad \text { Recoil/Warp }\end{array}$ \\
\hline \multirow{12}{*}{$\begin{array}{l}\text { SUS } \\
201\end{array}$} & \multirow{3}{*}{0,5} & C1-1 & - & - \\
\hline & & C1-2 & - & - \\
\hline & & C1-3 & - & - \\
\hline & \multirow{4}{*}{0,8} & C2-1 & - & $\sqrt{ }$ \\
\hline & & C2-2 & - & $\sqrt{ }$ \\
\hline & & C2-3 & - & $\sqrt{ }$ \\
\hline & & C3-1 & - & $\sqrt{ }$ \\
\hline & \multirow[t]{3}{*}{0,9} & C3-2 & - & $\sqrt{ }$ \\
\hline & & C3-3 & - & $\sqrt{ }$ \\
\hline & & C4-1 & - & - \\
\hline & \multirow{2}{*}{1,4} & C4-2 & - & - \\
\hline & & C4-3 & - & - \\
\hline
\end{tabular}

Berdasarkan Tabel 3.3 pengujian hemming sheet metal spesimen SUS 201 tidak terjadi crack. Material dengan ketebalan $1 \mathrm{~mm}$ dan 1,2 $\mathrm{mm}$ terdapat recoil / warp. Hasil pengujian hemming pelat SUS 201 dengan ketebalan $0,5 \mathrm{~mm}$ berhasil dan tidak mengalami crack dan recoil / warp karena material memiliki sifat ulet yang dipengaruhi oleh kandungan nikel dalam struktur material SUS 201. Hasil pengujian hemming pelat SUS 201dengan ketebalan $2 \mathrm{~mm}$ berhasil dan tidak mengalami crack dan recoil / warp karena menggunakan dies khusus. 


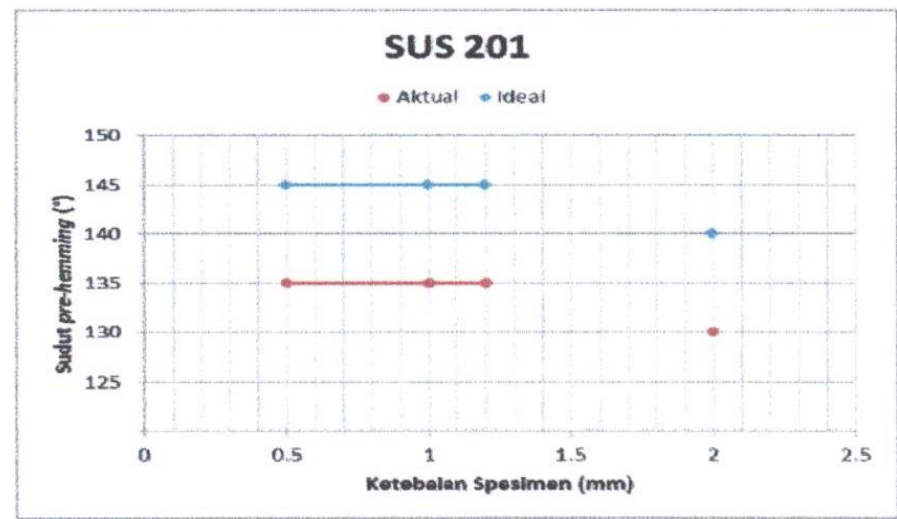

Gambar 3.5. Perbandingan sudut spesimen SUS 201 menggunakan tonase perhitungan dengan tonase perhitungan real.

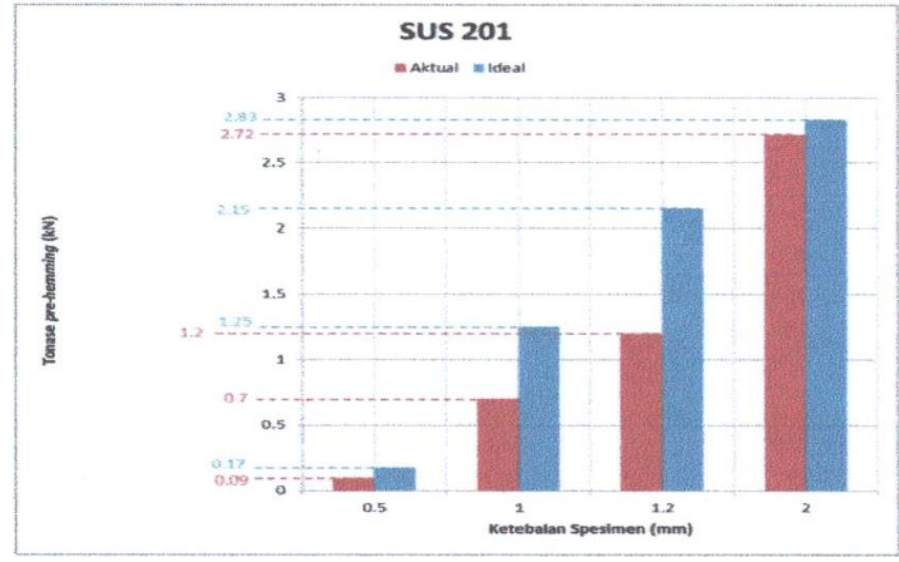

Gambar 3.6. Perbandingan tonase spesimen SUS 201 untuk mencapai sudut proses pre-hemming

Tabel 3.4. Tabel pengujian Hemming Material SUS 304

\begin{tabular}{|c|c|c|c|c|}
\hline \multirow{2}{*}{$\begin{array}{l}\text { Jenis } \\
\text { Pelat }\end{array}$} & \multirow{2}{*}{ Ketebalan (mm) } & \multirow{2}{*}{ Kode } & \multicolumn{2}{|c|}{ Kerusakan } \\
\hline & & & Crack & Recoil \\
\hline \multirow{15}{*}{304} & \multirow{3}{*}{0,5} & D1-1 & - & $\sqrt{ }$ \\
\hline & & D1-2 & - & $\sqrt{ }$ \\
\hline & & D1-3 & - & $\sqrt{ }$ \\
\hline & \multirow{4}{*}{1} & D2-1 & - & $\sqrt{ }$ \\
\hline & & D2-2 & - & $\sqrt{ }$ \\
\hline & & D2-3 & - & $\sqrt{ }$ \\
\hline & & D3-1 & - & $\sqrt{ }$ \\
\hline & \multirow{3}{*}{1,2} & D3-2 & - & $\sqrt{ }$ \\
\hline & & D3-3 & - & $\sqrt{ }$ \\
\hline & & D4-1 & - & $\sqrt{ }$ \\
\hline & \multirow{3}{*}{1,5} & D4-2 & - & $\sqrt{ }$ \\
\hline & & D4-3 & - & $\sqrt{ }$ \\
\hline & & D5-1 & - & - \\
\hline & \multirow[t]{2}{*}{2} & D5-2 & - & - \\
\hline & & D5-3 & - & - \\
\hline
\end{tabular}


Berdasarkan Tabel 3.4 pengujian hemming sheet metal pada spesimen SUS 304 tidak terjadi crack. Material dengan ketebalan $0,5 \mathrm{~mm} ; 1 \mathrm{~mm} ; 1,2 \mathrm{~mm} ; 1,5 \mathrm{~mm}$ terjadi recoil / warp. Hasil pengujian hemming pelat SUS 304 dengan ketebalan $0,5 \mathrm{~mm} ; 1 \mathrm{~mm} ; 1,2 \mathrm{~mm}$; $1,5 \mathrm{~mm}$ mengalami recoil / warp karena material memiliki sifat ulet yang dipengaruhi oleh kandungan nikel dalam struktur material SUS 304 [2]. Hasil pengujian hemming pelat SUS 304 ketebalan $2 \mathrm{~mm}$ berhasil di-hemming dan tidak mengalami crack dan recoil / warp karena menggunakan dies khusus.

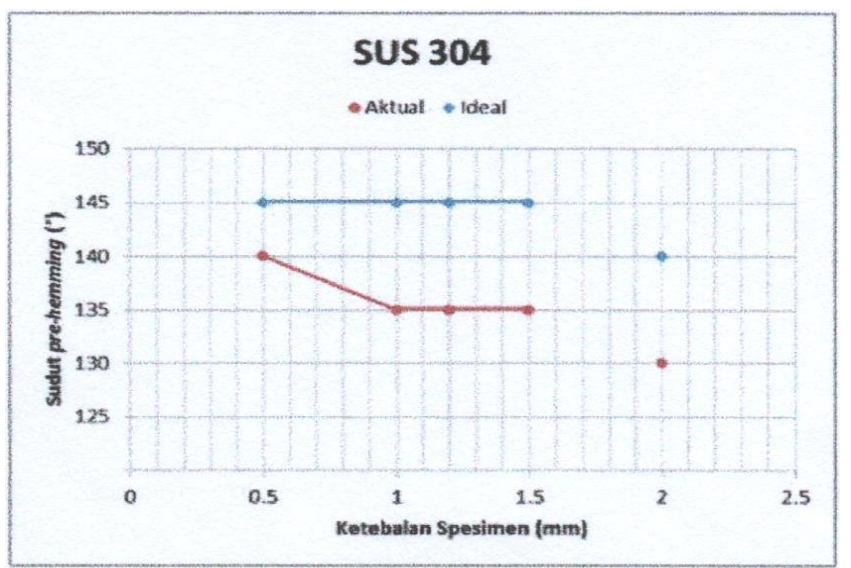

Gambar 3.7. Perbandingan sudut spesimen SUS 304 menggunakan tonase perhitungan dengan tonase real.

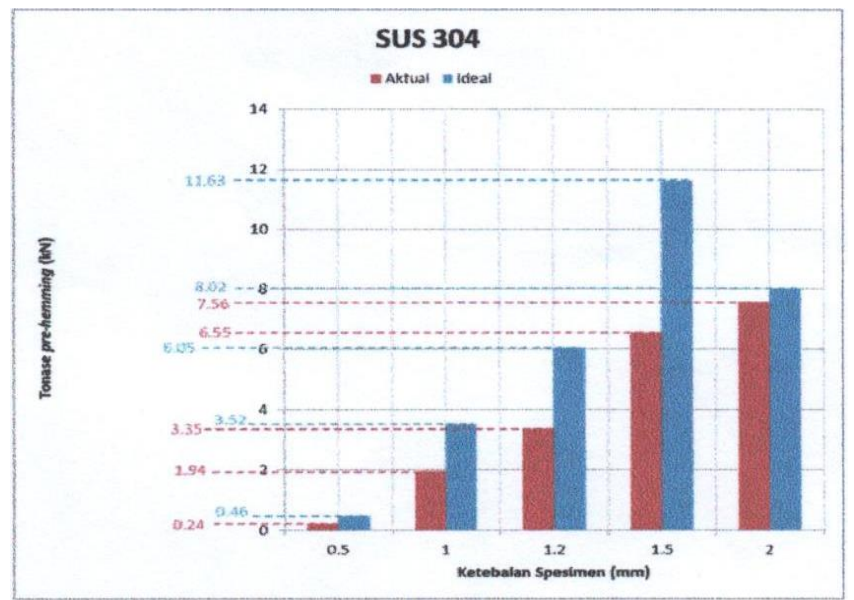

Gambar 3.8. Perbandingan tonase spesimen SUS 304 untuk mencapai sudut yang digunakan untuk pre-hemming

\section{KeSIMPULAN}

Berdasarkan analisis pengujian hemming sheet metal didapatkan kesimpulan proses hemming untuk jenis material SPHC, SPCC, SUS 201, dan SUS 304 dapat dilakukan di mesin AMADA PROMECAM dengan seri ITS 10030 T10508. Batas kemampuan hemming di mesin AMADA PROMECAM dengan seri ITS 10030 T10508 maksimal ketebalan 1,5 mm (semua jenis material), untuk ketebalan diatas $1,5 \mathrm{~mm}$ diperlukan punch dan dies khusus. Pengujian hemming untuk material SPHC dengan ketebalan diatas $3,5 \mathrm{~mm}$ cenderung terjadi crack. Pengujian hemming untuk material SPCC, SUS 201, dan SUS 304 cenderung terjadi recoil/warp. Tonase hemming material SPHC dan SPCC cenderung berimbang, sedangkan untuk material SUS 201 dan SUS 304 membutuhkan tonase yang lebih besar 
dari material mild steel karena kandungan nikel yang dimiliki lebih tinggi menjadikan material lebih ulet.

\section{Daftar Pustaka}

[1] Zahide Y, Hasmi, MSJ. Surface roughness measurement using an optical system. Journal of Materials Processing Technology. 1999; Vol. 88, Issues 1-3: 10-22

[2] Livatyali, H., Larris, S.J. Experimental investigation on forming defects in flat surfaceconvex edge hemming: Roll, recoil and warp. Journal of Materials Processing Technology. 2004; 153(1): 913-919

[3] Benson, Steve D. Press Brake Technology: A Guide to Precision Sheet Metal Bending. $1^{\text {st }}$ Edition. New York: SME. 1997.

[4] Reliance Foundry. 304 Stainless Steel. Canada: Reliance Foundry. 2017.

[5] Lange, K., Handbook of Metal Forming. Michigan: McGraw-Hill. 1985

[6] Sudibyo, B. Kekuatan dan Tegangan ljin. Surakarta: ATMI Press. 2017.

[7] Suroto, Ant. Strength of Material. Surakarta: ATMI Press. 2015.

[8] ASTM E290. Standard Test Methods for Bend Testing of Materials for Ductility, United States, 2014. 